\title{
Adoption of the New Primary School Curriculum in Zimbabwe: Implications for Staff Development and Quality Education
}

Douglas Gasva $(\mathrm{PhD})^{1 *}$, Rodney Joe Phiri ${ }^{2}$

${ }^{T}$ Quality Assurance Coordinator/Senior Lecturer, Mashonaland East Region, Zimbabwe Open University

${ }^{2}$ Media Studies Graduate, Matabeleland North Region, Zimbabwe Open University

\section{*Corresponding Author}

Dr. Douglas Gasva

\section{Article History}

Received: 16.06 .2020

Accepted: 25.06 .2020

Published: 06.07.2020

\begin{abstract}
This is a qualitative case inquiry that sought to interrogate the adoption of the new primary school curriculum in Zimbabwe; with the broader goal of determining its implications for staff development and the delivery of quality education. The study is predominantly an extract of a $\mathrm{PhD}$ in Educational Management thesis that was submitted to Zimbabwe Open University in 2019; with the thesis aiming at appraising the effectiveness of primary school staff development programmes in Hwange District of Matabeleland North Province in Zimbabwe; in pursuit for quality education. In undertaking the current study, the author was conjointly assisted in the collection of data by the co-author of this article. For the purpose of attainability, the study was delimited to only five schools in the area under study. The target population of the study were primary school educators and the sample comprised of 30 educators $(\mathrm{N}=30)$, made up of 25 classroom practitioners ( 5 per school) and the head teacher from each of the 5 study sites. Purposive sampling was used to identify participants; while Focus Group Discussions (FGDs) and Interviews were used to generate data. Consistent with phenomenological inquiries, data were analysed through interpretive phenomenological analysis (IPA); while findings were presented in summarised prose form. The key findings of the study were that the adoption of the updated curriculum had necessitated the need for teachers' professional development in order to equip them with the necessary knowledge and pedagogic skills which they generally lacked considering that the teachers did not study new learning areas of the curriculum during their initial teacher training. In addition, there was lack of knowledgeable and competent facilitators in the new learning areas of the updated curriculum, hence, the inevitable need for staff development. The researchers concluded that the adoption of the updated primary school curriculum had been a major spur for staff development for teachers; hence, brought a new trajectory where teachers' continuous professional development is a necessity rather than an option if quality education is to be realised. The researchers, therefore, recommend that the Ministry of Primary and Secondary Education (MoPSE) should sustain its support for the continual staff development of primary school teachers considering that the adoption of the new curriculum in Zimbabwe has important ramifications for the delivery of quality education.
\end{abstract}

Keywords: School curriculum, primary school educators, school staff development, quality education.

\section{BACKGROUND AND ITS SETTING Background to the study}

Consistent with global trends in education and due to the dynamic demands of the Zimbabwean community at large, the country considered reviewing and introducing an updated school curriculum as a way of fostering the long desired educational reform. This initiative was also in line with the nation's interest to advance the national agenda of a home-grown school curriculum based on an Afrocentric as opposed to a Eurocentric philosophy [1]. This idea was in line with the assertion that the radical reconstruction of education is essential for the socio-economic, cultural and political development of any nation [2]. Through needs analysis, baseline survey and stakeholder consultations; among other things; Zimbabwe, for a long time envisioned the provision of a new school curriculum, both at primary and secondary school level; that was meant to enhance the development of the country and mainly meet its post-independent socioeconomic developmental needs and aspirations [3]. For the bigger part of post-independent Zimbabwe, this rationality

Copyright @ 2020: This is an open-access article distributed under the terms of the Creative Commons Attribution license which permits unrestricted use, distribution, and reproduction in any medium for non commercial use (NonCommercial, or CC-BY-NC) provided the original author and source are credited. 
became portion of the national discourse which was considered within the contextual framework where education is essentially viewed as the major driver of national sustainable development and transformation.

In his official update on the proposed Zimbabwe New Curriculum Framework for Primary and Secondary Education 2015-2022, the then Minister of Primary and Secondary Education, elucidated that in line with the Recommendations of the Presidential Commission of Inquiry on Education and Training (CIET) in 1999; also dubbed as the 'Nziramasanga Commission'; the Ministry undertook an updating curriculum review exercise beginning October 2014 [4]. From that initiative, the Ministry developed the Zero Draft Curriculum Framework (ZDCF) for primary and secondary education which was meant to guide learning and teaching during the next seven years: 2015-2022. The new curriculum framework gives expression to national efforts as reflected in a number of citations including the 'Zimbabwe Agenda for Sustainable Socio-economic Transformation' (ZIMASSET), 'Zimbabwe's home-grown Constitution' as well as 'regional and international treaties' to which the country is a bonafide signatory [1]. The Government of Zimbabwe (GoZ), like most central governments across the globe, recognises that education is a basic human right and that it is an investment in human capital, which sustains and accelerates the rate of economic growth and socioeconomic development [5].

In addition, education simply fosters the maintenance of the social structure and also perpetuates the inculcation of fundamental societal values and attitudes [6]. Notably, the most crucial aspect of pre-colonial African education was its relevance to Africans in sharp contrast with that which was later introduced under colonialism [5]. The same source further clarify that at independence in 1980, Zimbabwe which changed its name from Rhodesia, inherited a two-tier racially structured education system which sought to protect the interests and domination of a White-ruling class of the pre-independent era; while African education was designed to perpetuate and reinforce the subjectivity and subjugation of indigenous Zimbabweans by a small White elite and kleptocracy. It was, therefore, largely on the basis of this antiimperialist philosophy that a decolonised education system was envisioned; which, was then, taken up through a revolution of the existing school curriculum in Zimbabwe that predominantly marginalised the interests and values of Africans while upholding Western sovereignty.

As noted in the Zimbabwe Ministry of Primary and Secondary Education New Curriculum Framework 2015 2022 Handbook [1], the rejuvenation of the old school curriculum and adoption of the updated one brought about improved access to quality education whose thrust is on assisting learners in their diverse areas of development and skill during and after their school life. It is in part within this phenomenal context that the traditional curriculum in Zimbabwe has since been replaced by a home-grown new curriculum largely rooted in the country's Afrocentric, humanistic and pragmatic philosophy of Unhu/Ubuntu; also known as Unhuism/Ubuntuism [5]. The same source notes that this newly adopted philosophy is essentially hinged on social values, patriotism, hard work and entrepreneurship. In the same vein, Dokora [3] says that the updated school curriculum is meant to modernize the educational system in line with new technologies, thereby producing learners with entrepreneurial skills who are also capable of creating employment as opposed to educating learners to be simply employed.

Education in post independent Zimbabwe, having been propagated by the 'mass education philosophy' (MEP), has however, been instrumental in the promotion of increased learning opportunities for the black majority, expanding knowledge and skills development. Remarkably, this saw the national literacy rate in independent Zimbabwe rising to as high as $91.4 \%$ by 2009 , thereby registering one of the highest literacy rates in Africa [7, 8]. However, as argued by Verwimp [9], the challenge for independent African countries such as Zimbabwe has not been only one of redressing the educational qualitative and quantitative imbalances in the inherited colonial education system, but also that of meeting the exceedingly high need for a re-orientation of Africans to an African-grown education system. Thus, the projected African education system, from which the Zimbabwe updated primary school curriculum based its tenets, is characterised by a high regard for African values, attitudes and practices as enshrined in the African narrative of Unhu/Ubuntu.

Even though the issue of the updated primary school curriculum in Zimbabwe was not one of the thematic areas of the doctoral study that was the basis for this study, it became one of the emerging issues during data generation in the research field. Accordingly, the author saw it fit not to ignore the concerns of participants as it tended to add value to the findings of the thesis. The researchers were enthralled by the participants' conviction that the adoption of the new primary school curriculum in Zimbabwe had important consequences for their professional development and the delivery of quality education. It is, therefore, against this backdrop that the current study was undertaken while; in particular, striving to determine the implications of this important phenomenal development on staff development and quality education from the perspective of insiders (i.e. primary school classroom practitioners and head teachers).

\section{Statement of the problem}

The adoption of the updated primary school curriculum in Zimbabwe was welcomed with mixed feelings by both educators and other stakeholders who include parents and the learners. The question at stake is 'what implications 
this phenomenal development has on staff development and the general quality of education in the primary school sector'? This problem is largely considered from the perspective of classroom practitioners and school heads considering that they are the ones directly involved in the implementation of the curriculum; hence, are key drivers in the success of this revolutionary educational initiative.

\section{Purpose of the study and Research questions}

The major purpose of this study was to interrogate the updated primary school curriculum in Zimbabwe in order to determine its implications for staff development and quality education from the primary school educators' perspective. The current study was premised on the following specific research questions:

i. What are the concerns of the primary school educators regarding the adoption of the updated curriculum in Zimbabwe?

ii. What are the implications of the introduction of the updated curriculum for the staff development of primary school teachers?

iii. What are the ramifications of the adoption of the updated curriculum for quality education in the country's primary school sector?

\section{Significance of the study}

The importance of the current study is hinged on the fact that it will bring out classroom practitioners and head teachers' concerns regarding the adoption of the updated curriculum. In addition, it will also reveal the ramifications associated with the adoption of the updated primary school curriculum for staff development and the general quality of education from the educators' perspective.

\section{REVIEW OF RELATEd LiteratuRE}

\section{Background and context of the updated primary school curriculum in Zimbabwe}

The definition of the term 'curriculum' is quite fluid; but generally, refers to the subjects, lessons and academic content taught in an educational institution or in a specific study programme. Depending on how broadly educators define or employ the term, curriculum also covers the knowledge and skills learners are expected to learn, which includes the learning standards or learning objectives they are expected to meet, content and lessons that teachers teach, assignments and projects given to learners, books, materials, presentations and readings used in a course, assessments and other methods used to evaluate student learning and performance [10]. As described by McBrien and Brandt [11] and the Indiana Department of Education [12], "a curriculum is a planned interaction of pupils with instructional content, materials, resources and processes for evaluating the attainment of educational objectives". A curriculum is not described merely in terms of how things ought to be, but how things are real within the school and in the classroom as well as how they may be applied in real life situations [13].

Before delving into the details of the updated primary school curriculum in Zimbabwe, it is important to give a synopsis of its context which also saves to complement the background to this study afore described above. Basically, the updated primary school curriculum incorporated the views and suggestions that were generated during a nationwide consultation process; where stakeholders urged the Ministry to spotlight essential subject areas, namely, Mathematics, Science, Technology, Vocational Studies, Heritage Studies and the Humanities. Such rationality is also underpinned by the fact that the expansion in the capabilities of information and communication technologies (ICT) and the emergence of an information-driven economy fortify the need for the development of new skill sets that enable learners and other citizens to live and work competitively in the global village [4].

The former President of the Republic of Zimbabwe, Robert Gabriel Mugabe, cited in the Parliament of Zimbabwe Handbook [14], in his national address in the 8th Session of the Parliament of Zimbabwe, had endorsed the idea of the New Curriculum Framework for Primary and Secondary Education in Zimbabwe: 2015-2022. In his speech, the former head of state impressed that there was critical need to transform the structure and curriculum of the country's education system in order to adequately meet the evolving developmental aspirations of the nation; which should see greater focus being placed on the teaching and learning of science, technology, engineering, mathematics and entrepreneurship [14]. This phenomenal stance was taken as a national license that heightened the development of the New School Curriculum in Zimbabwe; which saw the Ministry of Primary and Secondary Education leading the way in reviewing the primary and secondary school curriculum. This literally marked the adoption of the updated or new school curriculum in 2015 at the expense of the traditional curriculum which had been adopted since 1980 from the colonial Rhodesian regime.

The then former Minister of Primary and Secondary Education, Lazarus Dokora asserted that the Updated School Curriculum Framework: 2015-2022 mainly promotes the following core principles: inclusivity, relevance, respect and diversity. It is envisaged that this revitalized curriculum prepares graduates of the education system to have the following exit skills: critical thinking, problem solving, leadership, communication, team building and technological 
competence; among others [4]. The Framework outlines different learning areas at the primary school level. Thus, at the Infant Level (PSIL), these are; 1. Indigenous Language as medium of instruction; 2. Visual and Performing Arts (Expressive Arts); 3. Physical Education; 4. Mass Displays; 5. Mathematics and Science; 6. Social Studies (Family and Heritage Studies); and 7. Information and Communication Technology). At the Primary School Junior Level (PSJL), these are; 1. Languages; 2. Mathematics; 3. Social Studies; 4. Science and Technology; 5. Agriculture; 6. Information and Communication Technology; 7. Visual and Performing Arts; 8. Family, Religion and Moral Education; and 9. Physical Education, Sport and Mass Displays. Of note too is the fact that the Zimbabwe Updated School Curriculum Framework: 2015-2022 also emphasizes continuous assessment at all levels, that is, from Primary School Junior Level (PSJL) to Secondary School Advanced Level (SSAL) so that all learners' aptitudes and measurable competences are continually and gradually assessed. Thus, the Zimbabwean updated primary school curriculum, therefore, attempts to transcend the previous curriculum in its philosophical underpinnings, learner assessment criteria and anticipated learner outcomes.

\section{Conceptualising 'school staff development'}

'Staff development' is a broad concept as its precise definition depends on the institution and purpose for which it is meant. Generally, it refers to the process whereby employees of an organisation enhance their knowledge and skills in directions that are advantageous to their role in the organisation [15]. In the context of schools, staff development, therefore, entails planned activities within schools that are meant to assist teachers in attaining knowledge, new pedagogic skills, attitudes, values and dispositions; thereby gaining increased levels of professional competence for the benefit of learners and general school effectiveness [16]. Thus, in the context of this study, 'school staff development' covers the activities that develop primary school teachers' knowledge and expertise as well as other competencies that are beneficial to primary school learners and the wide-ranging attainment of quality education.

Accordingly; school staff development may be provided through several ways including induction and mentoring of primary school teachers, engaging the teachers in workshops, collaborative planning and teaching as well as sharing knowledge and skills in order to effectively deliver teaching services [17]. Such a conceptualisation of school staff development dovetails well with the current scenario in Zimbabwean primary schools where the professional development of teachers needs to focus more on equipping the teachers with knowledge and skills particularly for new learning areas and other aspects of the updated curriculum. Undertaking school staff development from that perspective would guarantee that the primary school teachers are enabled to effectively facilitate the teaching and learning process within and outside classrooms in as far as the whole enterprise is housed within a school curriculum.

\section{Nexus between curriculum upgrading, staff development and quality education}

Research in education generally reveals that there are often challenges in reaching large numbers of learners with quality learning content, even in cases where a home-grown, inclusive and robust curriculum is thought of as the solution. In addition, some evidence suggests that educational reform beyond pilot programmes often falters even when the pilot programmes were successful (Verwimp, ibid). However, educational reform and implementation of new curricular is most likely to succeed where not only schools are involved; but where the Ministry at large and the serving communities are involved, central government as well as educational agencies provide adequate resources for its development and implementation while also responding to national needs and aspirations [18]. However, budgetary constraints on the part of the relevant Ministry and central government and often create limitations in the successful implementation of various projects in schools including the introduction of a new curriculum. On the other hand, Alonsabe [19] reverberated by Liston [20] and Coombs and Manzoo [21] contend that school (such as administrative support and conduciveness of the teaching-learning environment) and teacher-based factors (such as teachers' knowledge, skills, interests and perceptions) are viewed as the most crucial factors in determining the success or failure of the implementation of a new curriculum or any such innovative educational project.

To be most effective, the attainment of quality education must be situated in a context of quality processes and collaboration between and among key stakeholders; in which case teachers should feature most as they are central to the implementation of new curricular $[22,23]$. Until recently, much discussion of educational quality centred on system inputs; such as infrastructure and pupil-teacher ratios, and on curricular content. In recent years, however, more attention has been paid to educational processes, including how teachers and administrators use inputs to frame meaningful learning experiences for students. However, teachers' roles and efficiency are often affected by different factors, one of which is the level of their knowledge and pedagogic skills as well as acceptance or not of the introduction of a new school curriculum [24]. As articulated by the Global Partnership in Education [25], several factors influence the successful implementation of a new school curriculum; and these include:

i. Teachers' professional knowledge and skills;

ii. Ongoing professional development for teachers;

iii. Active, standards-based teacher-learner participation methods;

iv. Teacher-learner feedback mechanisms; 


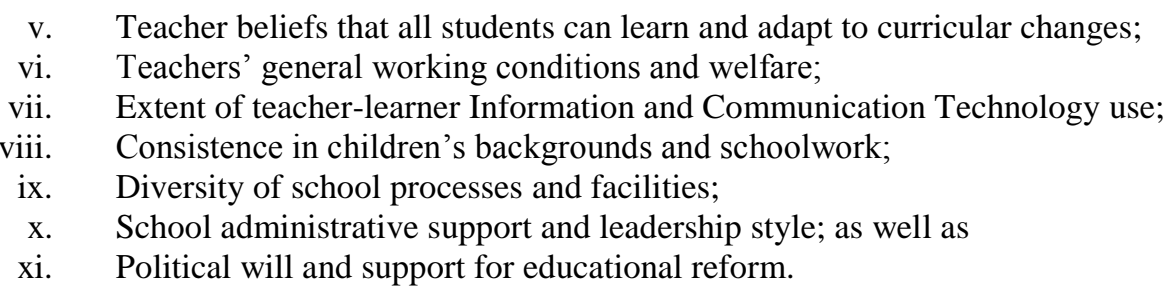

It is, therefore, important to note that while curriculum encompasses a wide variety of potential educational and instructional practices, educators often have a very precise, technical meaning in mind when they use the term; hence, most teachers often require staff development in order to study, discuss and understand curriculum issues. This is even more necessary if a curriculum is changed or updated as educators must acquire a new understanding of its content and expectations if they are to effectively deliver quality education [10].

\section{RESEARCH MeTHOdology}

This study adopted the qualitative research paradigm which the researchers found to be appropriate since a social problem needed to be explored and because the researchers needed a detailed understanding of the problem at stake $[26,27]$. The case study design was utilised and focused on five research sites which were all primary schools in Hwange District of Matabeleland North Province in Zimbabwe. The case study was preferred mainly because of its several advantages including, that it is concerned with a rich and vivid description of events relevant to a specific case and that it can establish phenomenal cause and effect; with the researchers observing implications including effects in the real or natural context $[28,29]$. Furthermore, this approach was ideal as it allowed for the generation of rich and thick data through illuminating participants' perceptions of their lived experiences [30]. Thus, the researchers' case in point was to interrogate primary school educators regarding the adoption of the updated curriculum in an effort to determine the implications of this development for staff development and quality education.

The target population of the study, which Kuhn [31] echoed by Marshall and Gretchen [32] view as the totality of all elements that conform to a set of specifications, comprising of the entire group of persons that are of interest to the researchers and to whom the research results can somewhat be generalized, comprised of primary school educators in the area under study. The study sample comprised of 30 educators $(\mathrm{N}=30)$, made up of 20 classroom practitioners and 5 head teachers who were drawn from the study sites in the area under study, with four teachers and the head from each of the five selected schools being part of the study. Purposive sampling technique under the non-probability sampling framework, which Best and Kahn [33] say that it essentially entails choosing the most qualifying individuals to serve as participants; ensures that the composition of the sample's elements has similar or related characteristics, was used. Using the sampling technique, the researchers were able to identify data rich sources $[34,35]$ in the form of primary school classroom practitioners and school heads as both groups of participants were directly involved in the implementation of the updated curriculum.

Focus group discussions (FGDs) were used to generate data from classroom practitioners while Interviews were used to gather data from the head teachers. Thus, FGDs and Interviews were the two data generation techniques used by the researchers to put together participants' concerns and views regarding the adoption of the updated school curriculum and its subsequent implications for staff development and the delivery of quality education. Notably, the researchers were the main media of data generation [36] as they engaged in interfacing with all the participants who provided the sought data. In that regard, Guba and Lincoln [37] assert that "... the qualitative researcher is as much a part of the inquiry as the intent of the study and the inquiry process". FGDs were preferred for classroom practitioners as they were cost effective and less time consuming as a number of participants (four per FGD) were involved in one discussion while interviews were preferred because they enabled the researchers to probe further to get head teachers' deep rooted views on the research problem in question [38]. The administration of both FGDs and Interviews involved the researchers engaging participants while they were within their schools and then documenting their responses. Before using these data collection tools, the researchers subjected them to pre-testing with teachers who were not part of the study which helped in the consolidation and improvement of the instruments [39].

Consistent with qualitative phenomenological inquiries, interpretive phenomenological analysis (IPA) of the generated data was done (Bailey, ibid), which involved the researchers carefully interpreting the generated data that had been provided by the different participants. The analysed data was then presented as findings in prose and point form which enabled the researchers to submit a summation of views that they considered critical in bringing out the nexus between the adoption of the updated primary school curriculum and staff development as well as quality education; thereby ensuring the trustworthiness and credibility of the findings [30]. Ethical principles including confidentiality and protecting the identity of participants (anonymity) were observed which gave the findings the professional integrity they deserved. The standing limitation of the findings was that, though they applied to primary schools studied, their 
generalisation to the rest of Zimbabwean primary schools is somewhat limited; which, however, was noted by the researchers to be consistent with qualitative case enquiries [40]; and therefore, of limited importance. In that regard, the researchers were, thus, convinced that the findings of this study would be quite useful in as much as they give a picture of how the adoption of the updated primary school curriculum in Zimbabwe has ramifications for staff development and the general delivery of quality education within the primary school sector.

\section{DisCUSSION OF FINDINGS}

Findings generated from use of focus group discussions with classroom practitioners

The following interpreted concerns by classroom practitioners were constructed following the moderation of five FGDs at the five primary schools. Thus, each set of views reflects what the teachers said in relation to how the updated school curriculum has implications for staff development and quality education:

$\boldsymbol{F G D}_{1}$ : As far as we are concerned, we are somehow ill-prepared to effectively implement the updated curriculum as we have limited understanding of some of its aspects particularly the teaching of the new learning areas. However, staff development has to some extent enabled us to adapt to the high demands of updated curriculum including expectations associated with the new learning areas.

$\boldsymbol{F G D}_{2}$ : In our case, we found staff development to be important in as much as it improves our knowledge and skills as teachers particularly regarding the new curriculum such as the teaching of new learning areas like Agriculture and Mass Displays. However, the updated curriculum has somehow brought new expectations and demands from us which we hope to meet with more and more staff development programmes to come.

$\boldsymbol{F G D}_{3}$ : We believe that the adoption of the updated curriculum should be complemented by our professional development so that we understand it better. However, the major challenge at this school is 'shortage of time'. Actually, we used to have staff development every Tuesday, but since the introduction of the new curriculum, this has not been the case as most of the time we have to grapple with understanding its new learning areas.

$\boldsymbol{F G D}_{4}$ : We need regular staff development because of the adoption of the updated curriculum, but the challenge is that with our school timetable that is 'overloaded', time is often not available for staff development. Our need for staff development is currently pronounced more than ever before due to the introduction of the new curriculum which has so many new learning areas we have to teach; yet we were not trained to teach them during teacher training.

$\boldsymbol{F G D}_{5}$ : We believe that most staff development programmes at this school have been quite effective all along, but since the adoption of the new curriculum, this has been compromised because the school is now faced with the challenge of having no qualified facilitators for the new learning areas since none of us studied these new learning areas during our teacher training at college. We believe that such a gap has serious negative effects on our ability to deliver education of excellence to the learners.

A further analysis of the different concerns by the classroom practitioners at the different FGD sites indicate that the adoption of the new curriculum has, in essence, necessitated teachers' need for their professional development. The teachers believed that this need was a function of the fact that the updated curriculum had come with it, new learning areas, which they have to teach yet they were not trained for them during their initial teacher training. Teachers also indicated that the staff development programmes that they had attended so far had been quite useful to them as they enhanced their knowledge and skills in the face of the high demands of the updated curriculum particularly because of the new learning areas.

\section{Findings generated from use of interviews with head teachers}

The following interpreted views by head teachers were also constructed following five interviews the researchers conducted at the selected primary schools. Thus, each set of views reflects what each participant said in relation to how the updated school curriculum has implications for the staff development of teachers and the general quality of education:

Head, school A: Staff development at this school has met a number of expected targets including producing teachers with new and updated information that is relevant to their work. I can actually say that staff development has helped teachers to understand, appreciate and overcome the demands of the new curriculum, such as effectively teaching new learning areas. 
Head, school B: The introduction of the new curriculum has led to the increased demand for conducting frequent staff development programmes in order to help teachers cope with its demands. This is particularly so if we are to consider that, the teachers we have in schools did not train for some of the new learning areas; which also poses the problem of lack of knowledgeable facilitators for the new learning areas.

Head, school B: There is need for our Ministry through schools, to educate teachers on the importance of participating in staff development sessions. Teachers need to develop a positive attitude towards staff development because with the introduction of the new curriculum, there is need for teachers to understand that it helps them to teach its new learning areas.

Head, school C: Our school generally lacks people who are qualified and experienced in certain areas particularly new learning areas which were introduced under the updated curriculum such as ICT, Mass Displays and Agriculture. Consequently, there is a shortage of suitable facilitators for staff development in such areas which affects the general quality of education in schools.

Head, school D: Shortage of time is one of the major challenges facing staff development at this school. I am sure that classroom practitioners will also agree with me that this challenge has been aggravated by the adoption of the new curriculum as its demands on teachers are just too high compared to the previous curriculum.

Head, school E: As a way of addressing challenges associated with the adoption of the updated curriculum, the Ministry may need to consider dropping some of the newly introduced learning areas and leave them for study in the secondary school. I am sure that will create more time for teachers particularly for their professional development considering that new learning areas are a challenge to most of them.

A further analysis of the views rose by head teacher's shows that they concurred on the fact that the adoption of the updated primary school curriculum in Zimbabwe had necessitated the need for teachers' continual professional development; which was also in agreement with the views of classroom practitioners. The head teachers impressed on the fact that staff development for teachers was important in order to equip the teachers with the necessary expertise which they generally lacked considering that they did not study new learning areas of the curriculum during their initial teacher training, yet, ironically, they were expected to teach them. Consequently, there was lack of knowledgeable facilitators in the new learning areas of the updated curriculum, hence, the further need for the teachers' professional development. The researchers also noted that sentiments raised in this study were consistent with earlier findings by Gasva and Moyo [41] and Mukomana, Mangozhe and Gasva [41]; who discovered that the adoption of the updated school curriculum had necessitated the need for staff development for teachers in order to enhance their capacity to handle the updated curriculum.

\section{CONCLUSION AND RECOMMENDATIONS}

Based on the findings, the study concluded that the adoption of the updated primary school curriculum in Zimbabwe had been a major spur for staff development for teachers considering that it came with new learning areas which the teachers did not study at college. This, therefore, brought a new national trajectory where teachers' continuous professional development is a necessity rather than an option if quality education is to be realised in the primary school sector. Accordingly, the researchers recommended the following to the MoPSE and primary schools:

i. The Ministry should ensure that all teachers within the primary school sector are oriented on the updated curriculum particularly the teaching of new learning areas;

ii. The Ministry should improve schools including electrifying them and connecting Internet so that teachers can access information on the updated school curriculum;

iii. Schools should identify and train staff development facilitators, particularly those who will be able to train others or facilitate on the teaching of new learning areas;

iv. Schools should consider teachers' professional development as formal education and training which deserves recognition and reward as it adds value to teachers' expertise.

\section{REFERENCES}

1. Zimbabwe MoPSE. (2016). New Curriculum Framework: 2015-2022 Handbook. Harare: Government Printers.

2. Chavhunduka, K., \& Moyo, C. (2003). Practicality of exemplary curriculum implementation material. Harare: UNICEF.

3. Dokora, L.D.K. (2016). New Curriculum implementation in Zimbabwe. Harare: MoPSE. 
4. Dokora, L.D.K. (2015). MoPSE Ministerial Statement: Update on the Proposed Curriculum Framework for Primary and Secondary Education2015-2022. Harare: MoPSE.

5. Shizha, E., \& Kariwo, M.T. (2011). Education and development in Zimbabwe: A social, political and economic analysis. Boston: SENSE.

6. Haralambos, M., \& Holborn, M. (2011). Sociology: Themes and perspectives. London: Harper Collins.

7. UNDP Baseline Survey. (2009). Education and global development. New York: UNDP.

8. UNESCO Study. (2011). Access to quality education. Washington-DC: UNESCO.

9. Verwimp, P. (2009). Measuring the quality of education: a case study of schools in rural Ethiopia. International Review of Education, 45(2), 167-196.

10. Great Schools Partnership. (2014). The glossary of education reform: hidden curriculum. Retrieved from http://Edglossary.Org/Hidden-Curriculum.

11. McBrien, J.L., \& Brandt, R. (1997). The language of learning: A guide to educational terms. Alexandria: VA ASCD.

12. Indiana Department of Education. (2016). Definitions of terms. Indiana Accountability System for Academic Progress, 2010. Retrieved on http://www.doe.in.gov/definitions.html.

13. Ellis, A.K. (2004). Exemplars of curriculum theory. Larchmount: NY. Eye in Education.

14. Parliament of Zimbabwe Handbook. (2013). Presidential National Address in the 8th Session of the Parliament of Zimbabwe. Harare: Government Printers.

15. Rouse, M. J. (2009). Continuing professional development. American Journal of Health-System Research, 61(2), 6976.

16. Glatthorn, A. (2011). Quality teaching through professional development. California: Corwin.

17. Mukomana, S., Mangozhe, N. and Gasva, D. (2017). In pursuit of the successful implementation of the new curriculum in Zimbabwe's primary and secondary schools. Scholars Journal of Arts, Humanities and Social Sciences, 5(9A) 156-164.

18. Belamy, C. (2010). The world's children and status report on quality education. New York: UNICEF.

19. Alonsabe, O.C. (2005). Curriculum implementation and enrichment. Innotech: SEMAO.

20. Liston, C. (2009). Managing quality standards in education. Burkingham: OUP.

21. Coombs, P.H., \& Manzoo, A. (2012). Quality in education: how education can help. Washington-DC: World Bank.

22. Dobrzanski, R. (2007). Quality management in education. Journal of Organisational Achievements, 24(2), $123-135$.

23. Fullan, M. (2011). The new meaning of educational change. New York: TCP.

24. Carron, G. \& Chau, T.N. (2008). The quality of schools in different development contexts. Paris: UNESCO.

25. Global Partnership in Education (2014). Barriers to quality education around the world. Geneva: UNDP.

26. Cohen, L., Manion, L. \& Morrison, K. (2007). Research methods in education. New York: Routledge.

27. Denzin, N.K., \& Lincoln, Y.S. (2012). Strategies of qualitative inquiry. Boston: CA Sage.

28. Crotty, M. (2008). The foundations of social research: Meaning and perspective in the research process. Boston: CA Sage.

29. Nisbet, J., Watt, J. (2009). Case study design. In J. Bell \& T. Bush. (2009). (eds). Conducting Small-Scale Investigations in Educational Management. London: Harper \& Row.

30. Creswell, J.W., \& Maietta, R.C. (2013). Qualitative research. Thousand Oaks: SAGE.

31. Kuhn R. (2006). Research in education. New York: Allyn \& Bacon.

32. Marshall, C., \& Gretchen, B.R. (2010). Designing qualitative research. New Delhi. SAGE.

33. Best, J.W., \& Kahn, J.V. (2003). Research in education. Boston: Allyn \& Bacon.

34. Bailey, K.D. (2004). Methods of social research. New York: The Free Press.

35. Steinke, I. (2014). Quality criteria in qualitative research. London: Sage.

36. Creswell, J.W. (2009). Qualitative inquiry and research design: Choosing among five approaches. Thousand Oaks: SAGE.

37. Guba, E. G., \& Lincoln, Y. S. (2011). The evaluator as instrument: effective evaluation. San Francisco: Jossey-Bass publications.

38. Frankel, J.R., \& Wallen, N.E. (2006). How to design and evaluate research in education. New York: McGraw Hill.

39. Patton, M.Q. (2012). Qualitative research and evaluation methods. London: SAGE.

40. Somekh, B., \& Lewin, C. (2010). Research methods in the social sciences. Alps: SAGE.

41. Gasva, D., \& Moyo, W. (2017). Teachers' views regarding the adoption of the new school curriculum in Zimbabwe: fostering quality education and national developmental needs. Scholars Journal of Arts, Humanities and Social Sciences, 5(5): 455-462.

42. Bernard, A. (2009). The child-friendly school: A summary paper written for UNICEF. New York: Harper and Collins.

43. International Working Group on Education. (2010). Defining quality in education. New York: UNICEF. 